\title{
Jean-Yves Pranchere, L'Autorité contre les Lumières. La philosophie de Joseph de Maistre
}

\section{Paola Salerni}

\section{(2) OpenEdition}

1 Journals

\section{Edizione digitale}

URL: http://journals.openedition.org/studifrancesi/33302

DOI: 10.4000/studifrancesi.33302

ISSN: 2421-5856

\section{Editore}

Rosenberg \& Sellier

\section{Edizione cartacea}

Data di pubblicazione: 1 décembre 2005

Paginazione: 652

ISSN: 0039-2944

Notizia bibliografica digitale

Paola Salerni, «Jean-Yves Pranchere, L'Autorité contre les Lumières. La philosophie de Joseph de

Maistre», Studi Francesi [Online], 147 (XLX | III) | 2005, online dal 30 novembre 2015, consultato il 20 avril 2021. URL: http://journals.openedition.org/studifrancesi/33302 ; DOI: https://doi.org/10.4000/ studifrancesi.33302

Questo documento è stato generato automaticamente il 20 avril 2021.

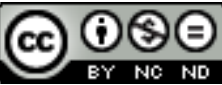

Studi Francesi è distribuita con Licenza Creative Commons Attribuzione - Non commerciale - Non opere derivate 4.0 Internazionale. 


\title{
Jean-Yves Pranchere, L'Autorité contre les Lumières. La philosophie de Joseph de Maistre
}

\author{
Paola Salerni
}

\section{NOTIZIA}

JEAN-YVES PRANCHERE, L'Autorité contre les Lumières. La philosophie de Joseph de Maistre, Genève, Droz, 2004, pp. 472.

1 Ripercorrendo l'opera di Joseph de Maistre, Jean-Yves Pranchère si muove fra i presupposti storici e i fondamenti ideologici e scientifici che ne hanno scatenato gli attacchi ai principi democratici della Rivoluzione francese, sottolineando che questo esemplare pensatore, vissuto nell'assolutismo, ha usato moduli espressivi del discorso morale imposti dalle condizioni coeve. Pur non negando la violenza di una scrittura che elogia la persecuzione in nome dell'«infaillibilité des chefs» (p. 13), per lo studioso le scelte politiche e morali, di impronta filosofica, potrebbero anticipare la critica agli Stati totalitari. Il lavoro, ricco di approfondimenti ed estremamente chiaro ed esauriente, delinea l'unità del pensiero maistriano, messo a punto nel 1794 ed espresso nel 1797 nelle Considérations sur la France, collocandolo fra «idéologie et philosophie»: la ricomposizione degli aspetti biografici e dei giovanili, violenti, toni massonici sono segnati da un organico «entre-deux», da una "triple "excentricité"» di natura geografica, sociale, culturale, fondamentale per capirne la posizione controrivoluzionaria assunta prima del 1794. Nato in Savoia, quindi di madrelingua francese, è suddito del re di Sardegna: collegato a due Paesi, ma equidistante dalle due capitali e dai loro centri di potere, vive in una periferia «à laquelle manque un centre» (p. 38) ed è dall"'estero" che segue la Rivoluzione. Di recente nobiltà, coronamento dell'ascesa sociale del padre, non condivide il mantenimento dei diritti feudali come la «noblesse héréditaire». Divenuto «émigré» per essere fuggito dall'invasione francese della Savoia, il Direttorio e l'Impero gli confermano che l'idea rivoluzionaria è essenzialmente 
imperialista e guerriera. Lo strano nazionalismo francese è inscritto nel Préambule della Déclaration des droits de l'homme et du citoyen, per il quale un gruppo particulier si istituisce depositario dei diritti universali dell'umanità, assegnandole i caratteri di una nazione che, pertanto, sarà universalizzata con un'incessante minaccia militare. Nelle Lettres d'un Royaliste savoisien descrive i rivoluzionari come dei «sauvages décivilisés» (p. 59) e il preteso principio d'uguaglianza inscritto nei diritti genera solo mostruose «fictions» destinate ad approfondire la disuguaglianza degli uomini: Maistre denuncia la democrazia come il peggiore dei dispotismi.

2 L'opera della maturità celebra il legame di religione e sovranità perché la religione di Stato deve essere religione dello Stato, facendo di quest'ultimo un oggetto di adorazione possibile se diventa un'autentica realtà religiosa, di origine divina. Solo riappropriandosi del principio della loro legittimità, distanziandosi da Napoleone e dalle altre monarchie di nascita rivoluzionaria, le monarchie europee per "diritto divino" riconquisteranno lo spirito autentico della loro sovranità.

Non perdendo mai di vista tutti gli orientamenti critici sul pensiero di Joseph de Maistre, Pranchère ne evidenzia il «mauvais esprit» e la marcata inclinazione alla provocazione tanto ammirata da Baudelaire: pur nell'eccesso, la sua opposizione ai valori illuministici è coerente. Nutrito di una profonda fede tradizionalista, elabora uno storicismo che talvolta pare annunciare l'approccio sociologico ed etnologico, rilevando però la natura e i limiti degli ideali delle Lumières, soprattutto nei ritratti di Rousseau e Voltaire contenuti nelle Soirées de Saint-Pétersbourg, con toni che prediligono l'invettiva all'argomentazione. Monarchia e cattolicesimo sono per lui l'incarnazione del principio dell'autorità metafisica di Dio, compiuti nell'espressione dell'autorità politica del sovrano, sacra perché di diritto divino, e dall'autorità papale: l'autorità è da lui definita come la base del sistema. Nell'ultimo capitolo Pranchère approfondisce il rapporto di Maistre tra storia e provvidenza: in risposta al secondo Discours di Rousseau, per il filosofo la fede e la certezza della Providence restituiranno all'Europa "moderna"; imbarbarita dalla rivoluzione e dal protestantesimo, l'«extrême civilisation» del XVIII secolo, placando le inquietudini scaturite dalle critiche antireligiose, ritrovando unità e stabilità nella lingua edenica perduta dagli uomini prima con il diluvio e poi con Babele. 